upper surface (Figs. 1 and $2 B$ ). The part of the arm board in contact with the semicircle is also beveled at the expense of its under surface. The stationary semicircular piece and the movable arm board are held together at this beveled joint by a small board beneath the arm board, which is attached to the arm board and to a screw in the center of the fixed semicircular piece (Fig. $2 E$ ).

The arm board is supported by a board running from the upright attached to the operating table to the outer end of the arm board. In order to allow rotation of this piece, a ball and socket joint is provided at its junction with the upright attached to the operating table (Figs. 1 and $2 \mathrm{C}$ ).

To allow a change of position of the patient's arm in the vertical plane, a superimposed board, the same size as the arm board and supported by four legs, is employed. These supports run through slots in the arm board proper; and by means of pegs inserted in holes in the supports, the outer or inner end or both ends of the superimposed board may be raised. This superimposed board may be removed entirely, but we have found it to have definite advantages in obtaining stability of the patient's arm.

The degree of adjustability of the board in the horizontal plane, increasing the abduction or adduction of the arm, is shown in the accompanying illustrations. In the illustrations the foreshortening lessens the apparent degree of rotation, which may be seen by noting the change in the patient's axillary fold.

\section{A CASE OF CONGENITAL MALFORMATION OF THE LEFT FOREARM WITH ABSENCE OF THE HAND}

\section{J. J. Kurlander, M.D., Cleveland}

B. C., a boy, aged 9 years, is healthy and normal in all respects except for the left upper extremity, which at first sight resembles very closely an intra-tuterine amputation

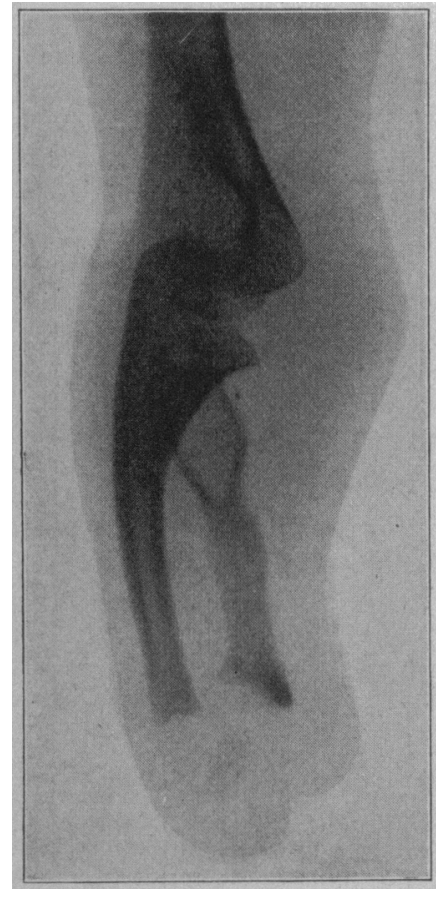

Fig. 1.-Congenital malforma tion of forearm, lateral view.

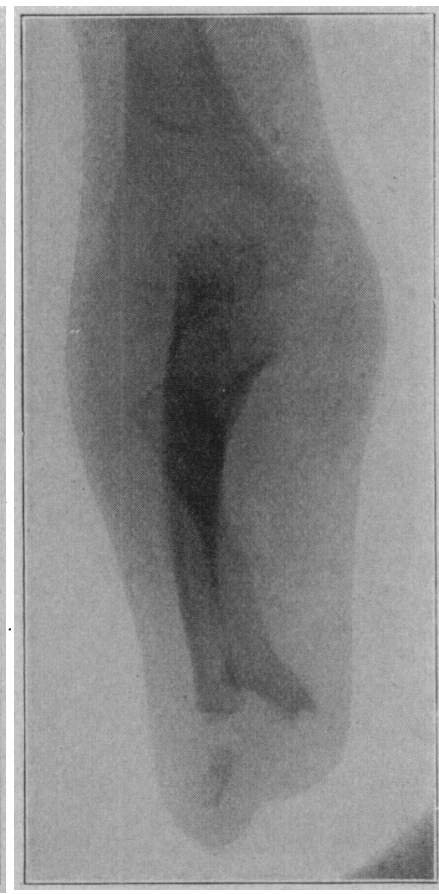

Fig. 2.-Congenital malformaFig. 2.-Congenital malforma-
tion of forearm, anteroposterior tion through the upper third of the forearm. The humerus is normal in size and function. There is normal range of motion at the elbow. The radius and ulna are palpable, and at their distal end is a small piece of bone, to which is attached a flexor and an extensor tendon. This small bone, evidently a rudimentary metacarpal bone, can be very easily flexed and extended. The stump is well shaped and padded.

The roengenograms show that the condition is not an intrauterine amputation, since both the radius and the ulna are practically perfectly formed, being only half or one third the normal length. There is complete absence of carpal and metacarpal bones, with the exception of the single rudimentary metacarpal bone, and absence of phalanges. When the boy becomes older, an artificial arm will be ordered.

630 Osborn Building.

\section{HERNIA OF THE ENTIRE STOMACH, RESULTING FROM STAB WOUNDS, SUCCESSFULLY REDUCED} WITH RECOVERY

Carlos C. Booth, M.D. Youngstown, Ohio Surgeon, Youngstown Hospital

During my recent term of service, I was called at 4 a. m., Oct. 1, 1918, to see J. L., aged 41, a laborer, who had just been brought into the hospital. He had a projecting tumor immediately over the region of the stomach covered only by clothing. On inquiry, I learned that he had been in a drunken brawl the night before, and on his way home had become involved in a fight with his companion, who stabbed him in the region of the stomach and that he had fallen

to the ground and had remained there until about $3 \mathrm{a} . \mathrm{m}$., when he was found by passers-by who sent him to the hospital

On examination this tumor proved to be the stomach protruding through the wound. It was nearly perfectly round dark red, and measured about 10 inches in diameter and was strangulated. A photograph was taken at once by artificial light, after which I had the patient etherized and the tumor elevated as much as possible and turned from one side to the other. The skin was painted with a 5 per cent. solution of iodin beneath the tumor to the edges of the wound, after which the tumor was thoroughly cleansed with saline solution. The lower edge of the stab wound was enlarged. I found that the tumor consisted simply of the entire stomach, and that the stab wound was $1 \frac{1 / 2}{2}$ inches long diagonally and just beneath the ensiform cartilage, the wound severing the rectus muscle on both sides of the median line. The stomach was gradually reduced into the abdomen, the wound was cleansed with iodin, and the wound layers were sutured, the wound being entirely closed.

The patient made an uneventful recovery with the exception of a stitch abscess which caused some delay in the healing of the wound. He was discharged about November 1, well.

The little white marks seen on the tumor are due to the movements of the tumor during respiratory movement while the photograph was being taken.

Code of Lighting for Industrial Plants.-Public Health Reports, Jan. 24, 1919, contains the report of the divisional committee on lighting, section on sanitation, committee on welfare work of the committee on labor, advisory commission, Council of National Defense. It includes a set of rules officially approved by the Illuminating Engineering Society which have been tried out for several years under working conditions in factories, mills and other work places, and which constitutes the basis of the Pennsylvania factory lighting code and that of New Jersey, which went into effect in both states during 1916. The effects of good light in factories are thus set forth in the reports: reduction of accidents greater accuracy in workmanship; decreased spoilage of product; increased production for the same labor cost; less eye strain; better working and living conditions; greater contentment of the workmen; better order, cleanliness, and neatness in the plant; easier supervision of the men. The article is illustrated, and is an important contribution to the subject of proper light in industrial plants. 